\title{
UJI AKTIVITAS EKSTRAK KLOROFORM DAUN SANGKAREHO (Callicarpa longifolia Lam.) TERHADAP PENYEMBUHAN LUKA SAYAT PADA TIKUS JANTAN GALUR WISTAR
}

\section{Activity Test Of Chloroform Extract Sangkareho (Callicarpa Longifolia Lam.) Leaf On Wound Healing In Male Wistar Rats}

\section{Theresia Carolina ${ }^{1 *}$ \\ Dyan Fitri Nugraha ' \\ Umi Hanik Fetriyah ${ }^{2}$}

\begin{abstract}
*IPharmacy Departement, Health Faculty, Sari Mulia University, Banjarmasin City, Sounth Borneo 70238, Indonesia
\end{abstract}

2 Nursing Departement, Health Faculty, Sari Mulia University, Banjarmasin City, Sounth Borneo 70238, Indonesia

*email:

carolinatheresia2808@gmail.com

\section{Kata Kunci:}

Daun Sangkareho (Callicarpa longifolia Lam.)

Ekstrak kloroform

Luka sayat

Penyembuhan luka

\section{Keywords:}

Sangkareho (Callicarpa longifolia Lam.)

leaf

Chloroform extract

Incision wound

Wound healing

\begin{abstract}
Abstrak
Luka yang tidak ditangani dapat menimbulkan kejadian infeksi dan akibat terburuknya adalah kematian. Sementara itu, masyarakat di Kalimantan Tengah menggunakan daun Sangkareho (Callicarpa longifolia Lam.) sebagai obat luka tanpa adanya bukti secara ilmiah. Penelitian ini bertujuan untuk menganalisis aktivitas ekstrak kloroform daun Sangkareho (Callicarpa longifolia Lam.) terhadap penyembuhan luka sayat pada tikus jantan galur wistar. Penelitian ini menggunakan metode penelitian kuantitatif true eksperimental dengan rancangan post test only control group design. Sampel berupa tikus jantan galur wistar berjumlah 25 ekor dipilih acak menjadi 5 kelompok. Tikus dilukai sepanjang 10 $\mathrm{mm}$ kedalaman $2 \mathrm{~mm}$ di regio vertebralis thoracis dan regio interscapularis. Pengumpulan data berdasarkan observasi luka sayat selama 10 hari (perubahan panjang luka dan fase luka). Analisis statistik menggunakan uji kruskal wallis dan uji mann whitney. Hasil yang diapatkan adalah ekstrak kloroform daun Sangkareho (Callicarpa longifolia Lam.) dosis $200 \mathrm{mg} / 200 \mathrm{grBB}$ memasuki fase remodeling dengan panjang luka $0 \mathrm{~mm}$ pada hari keenam lebih cepat dibandingkan kontrol positif. Hasil analisis data statistik menunjukan terdapat perbedaan signifikan antara kelompok ekstrak kloroform daun Sangkareho (Callicarpa longifolia Lam.) dosis $200 \mathrm{mg} / 200 \mathrm{grBB}$ dengan kelompok kontrol positif. Kelompok ekstrak kloroform daun Sangkareho (Callicarpa longifolia Lam.) dosis $200 \mathrm{mg} / 200 \mathrm{grBB}$ lebih cepat membantu penyembuhan luka dibandingkan kontrol positif berdasarkan perubahan panjang luka dan fase luka. Penyembuhan luka diduga karena adanya senyawa metabolit sekunder pada daun Sangkareho (Callicarpa longifolia Lam.).
\end{abstract}

\begin{abstract}
Wounds that are not treated properly could lead to infections and the worst result would be deadth. Meanwhile, people in Central Kalimantan use the Sangkareho (Callicarpa longifolia Lam.) leaf as wound medicine without any scientific proof. Research aims to analyze activity chloroform extract of Sangkareho (Callicarpa longifolia Lam.) leaf on wound healing in male wistar rats. This research used true experimental method with post test only control group deisgn. The sample is 25 male wistar rats that were randomly selected into 5 groups. Rats were wounded by $10 \mathrm{~mm}$ incision wound with depth $2 \mathrm{~mm}$ in regio vertebralis thoracis and regio interscapularis. Data collection based on observed the incision for 10 days (changed in wound length and wound phase). Statistically analysis used kruskal wallis test and mann whitney test. The results is chloroform extract of Sangkareho (Callicarpa longifolia Lam.) leaf dose $200 \mathrm{mg} / 200 \mathrm{grBW}$ enter remodeling phase with wound length $0 \mathrm{~mm}$ on sixth day faster than positive control. The results of statistical data analysis show significant difference between chloroform extract of Sangkareho (Callicarpa longifolia Lam.) leaf dose $200 \mathrm{mg} / 200 \mathrm{grBW}$ group and positive control group. Chloroform extract of Sangkareho (Callicarpa longifolia Lam.) leaf dose $200 \mathrm{mg} / 200 \mathrm{grBW}$ group help wound healing faster than positive controls based on change on wound length and wound phase. Wound healing suspected because secondary metabolites in Sangkareho (Callicarpa longifolia Lam.) leaf.
\end{abstract}




\section{PENDAHULUAN}

Berdasarkan hasil Riskesdas tahun 2018 terjadi kenaikan kejadian luka di Indonesia dibandingkan dengan tahun 2013 dengan presentase kenaikan dari 8,2\% menjadi 9,2\% (RISKESDAS, 2018). Luka termasuk kondisi rusaknya jaringan kulit di bagian tubuh terutama area sekitar luka. Luka merupakan sebuah gangguan kontinuitas sel-sel atau jaringan tubuh. Luka sayat termasuk jenis luka yang banyak ditemui, cedera traumatik menimbulkan terjadinya luka sayat yang berakibat kulit menjadi robek atau kehilangan jaringan disekitar daerah yang terkena luka. Luka sayat dapat terjadi akibat terkena benda tajam seperti pisau (Kurniawaty et al., 2018).

Tubuh yang mengalami luka, akan ada mekanime alami dari tubuh untuk memulihkan jaringan pada kulit yang rusak dan terbentuk struktur jaringan yang baru. Faktor dari dalam seperti nutrisi, sistem imun, penggunaan obat serta kondisi metabolik berpengaruh dalam proses tersebut (Handi et al., 2017). Penyembuhan luka atau cedera akan mengalami ada 3 fase atau 3 tahapan mekanisme pemulihan dari luka yaitu fase inflamasi, dilanjutkan fase proliferasi dan terakhir fase remodeling. Kondisi yang dimulai ketika kulit mengalami cedera/luka, biasanya fase ini berlangsung selama 2 hingga 3 hari dari awal terkena luka disebut dengan fase inflamasi. Pada hari keempat hingga minggu ketiga setelah kulit mengalami luka terjadi pembentukan jaringan baru di daerah sekitar luka yang dinamakan fase proliferasi. Fase terakhir pada proses penyembuhan luka ditandai dengan pembentukan kolagen di daerah luka dinamakan fase remodeling (Sinto, 2018).

Kejadian infeksi piogenik ditimbulkan akibat dari luka yang tidak segera diberi pengobatan, infeksi ini ditandai dengan adanya pembengkakan dan terdapat nanah. Infeksi ini disebabkan oleh mikroorganisme yang memasuki jaringan kulit pada luka sehingga dapat menyebabkan berbagai penyakit seperti impetigo, osteomyelitis, sepsis dan kematian. Komplikasi ini diakibatkan bakteri Staphylococcus aureus yang menimbulkan kejadian infeksi (Ekawati et al., 2018).

Infeksi yang terjadi akibat adanya mikroorganisme atau bakteri pada luka dapat dicegah dengan menggunakan terapi farmakologi yang bersifat antimikroba. Luka sayat dapat ditangani dengan terapi farmakologi menggunakan obat sintetis atau obat tradisional. Tumbuhan berpotensi sebagai tumbuhan obat dari Kalimantan Tengah salah satunya adalah Sangkareho (Callicarpa longifolia Lam.) yang merupakan tumbuhan yang banyak tumbuh di Kalimantan dan merupakan salah satu dari kearifan lokal masyarakat Kalimantan yang dapat digunakan sebagai antiluka. Daun adalah bagian dari tumbuhan Sangkareho (Callicarpa longifolia Lam.) yang digunakan sebagai antiluka (Handayani \& Natasia, 2018).

Daun Sangkareho (Callicarpa longifolia Lam.) dimanfaatkan oleh masyarakat Kalimantan Tengah secara turun-temurun sebagai pengobatan luka luar, diare, dan pendarahan pasca melahirkan (Handayani \& Natasia, 2018). Menurut hasil dari penelitian yang sudah dilakukan peneliti lain sebelumnya didapatkan bahwa simplisia daun Sangkareho (Callicarpa longifolia Lam.) yang di ekstraksi menggunakan pelarut etanol memiliki kandungan alkaloid, flavonoid, dan steroid. Senyawa metabolit sekunder ini berpotensi membantu proses penyembuhan luka (Qamariah et al., 2016; Saputra, 2016). Ekstrak etanol daun Kerehau (Callicarpa longifolia Lamk.) berupa sediaan gel dengan konsentrasi $20 \%$ memiliki aktivitas antiluka terhadap penyembuhan luka sayat yang dialami kelinci (Susilawati et al., 2018).

Menurut penelitian yang dilakukan oleh (Qamariah et al., 2016) pelarut non polar merupakan sistem pelarut yang mempunyai sifat kepolaran yang cocok dengan sifat kepolaran komponen senyawa kimia yang terkandung di dalam daun Sangkareho (Callicarpa longifolia Lam.) salah satu contoh pelarut non polar adalah kloroform. Penelitian sebelumnya belum ada peneliti yang meneliti aktivitas daun Sangkareho 
(Callicarpa longifolia Lam.) terhadap luka sayat dengan menggunakan pelarut non polar dalam proses ekstraksi daun Sangkareho (Callicarpa longifolia Lam.), sehingga peneliti tertarik untuk menganalisis aktivitas ekstrak kloroform daun sangkareho (Callicarpa longifolia Lam.) terhadap penyembuhan luka sayat pada tikus jantan galur wistar dilihat dari perubahan panjang luka dan fase luka yang dialami hewan uji.

\section{METODOLOGI}

Alat dan Bahan

Alat yang digunakan pada penelitian ini adalah kertas saring, timbangan analitik (Shimadzu corporation), seperangkat alat maserasi, rotatory evaporator (Dragon Lab), hot plate (Thermo Scientific), corong kaca (Pyrex), gelas ukur $10 \mathrm{ml}$ (Pyrex), beker glass $250 \mathrm{ml}$ (Pyrex), tabung reaksi (Pyrex), rak tabung reaksi, pipet tetes, sendok tanduk, batang pengaduk, alat pencukur bulu, pisau, toples kaca, pisau bedah (Gea Medical), kandang tikus, gunting, alat tulis, sarung tangan kain, dan handscoon (Sensi).

Bahan yang digunakan pada penelitian ini adalah Daun Sangkareho (Callicarpa longifolia Lam.), tikus jantan galur wistar berusia 3-4 bulan dengan berat badan 190250 gram, lidokain, alkohol swabs, kasa steril, alkohol $70 \%$, pereaksi Mayer, serbuk Magnesium, larutan aseton, serbuk halus asam oksalat, serbuk halus asam borat, $\mathrm{HCl}, \mathrm{NaCl} 10 \%, \mathrm{Na}$ CMC 0,5\%, Pereaksi Liebermann Burchard, Gelatin, Kloroform, povidone iodine, dan aquadest.

\section{Metode Penelitian}

Pengelolaan Simplisia

I. Pengumpulan Bahan Baku

Tumbuhan Sangkareho (Callicarpa longifolia Lam.) didapatkan di perkebunan milik warga yang tinggal di daerah Tumbang Baringei, Kuala Kurun, Kalimantan Tengah.

\section{Sortasi Basah}

Bagian tumbuhan yang tidak digunakan dan kotoran yang menempel pada sampel dipilah dan dipisahkan dari sampel (Supomo et al., 2016).

3. Pencucian

Pencucian dilakukan menggunakan air mengalir untuk memastikan tidak ada kotoran yang menempel pada sampel tumbuhan (Supomo et al., 2016).

4. Perajangan

Perajangan dilakukan untuk memperkecil ukuran daun Sangkareho (Callicarpa longifolia Lam.). Perajangan dilakukan dengan menggunakan pisau (Supomo et al., 2016).

\section{Pengeringan}

Pengeringan daun Sangkareho (Callicarpa longifolia Lam.) dilakukan dengan cara diangin-anginkan pada tempat yang terlindung dari sinar matahari (Supomo et al., 2016).

6. Sortasi Kering

Daun Sangkareho (Callicarpa longifolia Lam.) yang sudah kering dipilah untuk memisahkan kotoran yang ada atau menempel di simplisia ketika proses pengeringan.

7. Penyimpanan

Siapkan wadah untuk menyimpan simplisia daun Sangkareho (Callicarpa longifolia Lam.) yang sudah ditimbang.

\section{Ekstraksi}

Simplisia daun Sangkareho (Callicarpa longifolia Lam.) dimasukan kedalam bejana maserasi untuk selanjutnya dimasukan pelarut yaitu kloroforom. Pelarut tersebut diganti setiap $3 \times 24$ jam, maserasi dilakukan dalam kurun waktu 3 hari kemudian dilanjutkan dengan proses remaserasi selama 3 hari.

Hasil ekstraksi dikumpulkan lalu disaring hingga didapatkan ekstrak cair. Ekstrak cair tersebut dimasukan kedalam rotary evaporator agar didapatkan ekstrak kental. Ekstrak kental daun Sangkareho 
(Callicarpa longifolia Lam.) yang sudah jadi disimpan di wadah.

\section{Skrining Fitokimia}

\section{Alkaloid}

Prosedur kerja pengujian alkaloid adalah Tabung reaksi diisi dengan $\mathrm{I} \mathrm{ml}$ ekstrak yang sudah disediakan, kemudian tambahkan 2-3 tetes pereaksi Mayer. Apabila ekstrak mengandung alkaloid maka akan timbul warna putih atau kuning keruh pada ekstrak (Julianto, 2019).

\section{Flavonoid}

Pengujian flavonoid dengan Ekstrak ditambahkan kedalam tabung reaksi sebanyak I ml kemudian larutan ekstrak tersebut diuapkan sampai mengering, sisa dari ekstrak kemudian dibasahkan dengan larutan Aseton. Tahap selanjutnya masukan serbuk halus asam borat secukupnya secara perlahan dan tambahkan juga serbuk halus asam oksalat kedalam larutan ekstrak dan dipanaskan secara hati-hati di penangas air. Setelah dipanaskan tambahkan eter sebanyak $10 \mathrm{ml}$ dan diamati dibawah sinar UV $366 \mathrm{~nm}$. Apabila positif mengandung flavonoid maka akan terbentuknya larutan yang berfluoresensi kuning intensif ketika di sinari oleh sinar UV (Lolok et al., 2020).

3. Tanin

Pengujian tanin, ekstrak diambil sebanyak I ml ditambahkan kedalam tabung reaksi. Tambahkan larutan gelatin secukupnya kemudian tambahkan 35 tetes $\mathrm{NaCl}$ 10\% pada tabung reaksi berisi sampel. Apabila ekstrak positif mengandung tanin, akan terlihat endapan putih kekuningan pada sampel (lkalinus et al., 20I5)

4. Saponin

Pengujian saponin, ekstrak diambil secukupnya lalu masukan kedalam tabung reaksi dan tambahkan 10 $\mathrm{ml}$ aquadest yang telah dipanaskan sebelumnya. Dinginkan sebentar dan lakukan penggojokan selama 10 detik. Apabila terlihat ada buih yang tingginya $\mathrm{I}-10 \mathrm{~cm}$ yang timbul tidak hilang selama 10 menit segera tambahkan I tetes $\mathrm{HCl} 2 \mathrm{~N}$. Amati reaksi yang terjadi, apabila buih tidak hilang maka sampel positif mengandung saponin (Lestiono et al., 2020).

5. Steroid

Pengujian steroid, tabung reaksi diisi dengan $2 \mathrm{ml}$ ekstrak dan ditambahkan kloroform sebanyak I ml. Tambahkan pereaksi Liebermann Burchard secukupnya. Amati perubahan warna yang terjadi, apabila timbul sebuah cincin berwarna hijau kebiruan maka sampel mengandung senyawa steroid (Sami et al., 2019).

\section{Penyiapan Hewan Uji}

Tikus jantan galur wistar sehat tanpa adanya luka atau cacat, berkelamin jantan dengan berat badan 190-230 gram sebanyak 25 ekor dibagi secara acak menjadi 5 kelompok yang terdiri dari 5 ekor.

\section{Perlakuan Terhadap Hewan Uji}

Tikus jantan galur wistar ditempatkan dalam kandang yang terpisah dan diberi tanda berdasarkan masingmasing perlakuan dan di aklimatisasi selama I minggu ditempat penelitian untuk penyesuaian hewan uji dengan lingkungan. Hewan uji dibagi menjadi 5 kelompok dengan perlakuan sebagai berikut :

I. Tikus jantan galur wistar sebanyak 5 ekor diberikan larutan $\mathrm{Na}$ CMC 0,5\% pada luka sayat selama 10 hari.

2. Tikus jantan galur wistar berjumlah 5 ekor diberikan Povidone lodine pada luka sayat selama 10 hari.

3. Tikus jantan galur wistar sebanyak 5 ekor diberikan ekstrak daun Sangkareho (Callicarpa longifolia Lam.) $50 \mathrm{mg}$ pada luka sayat selama 10 hari.

4. Tikus jantan galur wistar sebanyak 5 ekor diberikan ekstrak daun Sangkareho (Callicarpa longifolia Lam.) $100 \mathrm{mg}$ pada luka sayat selama 10 hari. 
5. Tikus jantan galur wistar sebanyak 5 ekor diberikan ekstrak daun Sangkareho (Callicarpa longifolia Lam.) $200 \mathrm{mg}$ pada luka sayat selama 10 hari.

Setelah pembagian hewan uji maka dilakukan pembuatan luka sayat pada hewan uji yaitu dengan mencukur terlebih dahulu bulu diarea sekitar punggung tikus yang akan dilukai menggunakan alat pencukur sepanjang $20 \mathrm{~mm}$.

Bersihkan daerah yang akan dilukai menggunakan alkohol swabs agar area yang akan dilukai dalam kondisi steril dan mencegah kejadian infeksi. Tikus diberi anestesi lidokain yang dosisnya sudah dikonversi dari manusia ke tikus dengan rute subkutan.

Sayat penggung tikus menggunakan pisau bedah dengan panjang luka $10 \mathrm{~mm}$ dan kedalaman $2 \mathrm{~mm}$. Setelah itu berikan perlakuan berupa pengolesan sampel uji pada luka sayat sesuai dengan kelompok uji. Perlakuan diberikan setiap hari selama 10 hari.

Pengamatan pada luka sayat dilakukan Ix/hari setiap hari selama 10 hari. Pengamatan terhadap panjang luka dan ciri fase luka.

\section{Analisis Hasil Data Statistik}

Analisis data secara statistik menggunakan aplikasi SPSS dengan mengujikan uji normalitas pada data menggunakan Shapiro Wilk dan menggunakan uji Levene Test sebagai uji homogenitasnya dengan nilai perbedaan yang signifikan $(p>0,05)$. Data tidak terdistribusi normal tetapi homogen dilakukan pengujian non parametrik dengan menggunakan uji Kruskall Wallis kemudian dianalisis menggunakan Mann Whitney untuk melihat perbedaan yang signifikan antara dua kelompok berpasangan $(p<0,05)$.

\section{HASIL DAN PEMBAHASAN}

I. Skrining Fitokimia Ekstrak Kloroform Daun Sangkareho (Callicarpa Longifolia Lam.)

Pengujian skrining fitokimia dilakukan untuk mengetahui kandungan metabolit sekunder apa saja yang terkandung dalam ekstrak kloroform daun sangkareho (Callicarpa Longifolia Lam.).

Tabel I. Skrining Fitokimia Ekstrak Kloroform Daun Sangkareho (Callicarpa longifolia Lam)

Metabolit Sekunder Hasil Keterangan

$(+/-)$

\begin{tabular}{ccc}
\hline Alkaloid & + & Kuning keruh pada ekstrak \\
\hline Flavonoid & + & Terdapat flurosensi kuning \\
\hline Tanin & + & Terdapat endapan putih \\
\hline Saponin & + & Buih setinggi $1 \mathrm{~cm}$ \\
\hline Steroid & + & Cincin hijau kebiruan \\
\hline
\end{tabular}

Berdasarkan tabel I ekstrak kloroform daun sangkareho (Callicarpa longifolia Lam) setelah dilakukan skrining fitokimia mendapatkan hasil bahwa ekstrak kloroform daun sangkareho (Callicarpa longifolia Lam) positif mengandung Alkaloid, Flavonoid, Tanin, Saponin dan Steroid. Hasil penelitian sebelumnya mengatakan bahwa eluen non polar merupakan sistem pelarut yang cocok dengan sifat kepolaran senyawa kimia yang ada pada daun Sangkareho (Callicarpa longifolia Lam.) (Qamariah et al., 20I6).

Kandungan metabolit sekunder yang terdapat pada ekstrak kloroform daun sangkareho (Callicarpa longifolia Lam.) inilah yang diduga memiliki peran dalam proses penyembuhan luka sayat pada hewan uji. Metabolit sekunder seperti Alkaloid, Flavonoid, Tanin, Saponin dan Steroid memiliki mekanisme kerja yang berperan penting dalam proses penyembuhan luka. Alkaloid memiliki aktivitas antibakteri, antiinflamasi serta membantu dalam penyempitan pembuluh darah (vasokontriksi) di awal ketika terjadinya luka bertujuan untuk mengurangi pendarahan yang terjadi pada fase hemostasis dan inflamasi serta proliferasi (Bunganaen et al., 2020; Kemalasari et al., 2018).

Flavonoid memiliki peran sebagai antimikroba dimana dapat mencegah kejadian infeksi dengan menghambat bakteri masuk kedalam luka pada fase hemostasis, selain itu juga flavonoid berperan sebagai antiinflamasi dimana dapat mengurangi 
bengkak pada luka ketika luka mengalami fase inflamasi dan flavonoid juga memiliki aktivitas astrigen sehingga dapat meningkatkan penyembuhan luka dengan penyusutan luka yang membantu untuk mempercepat terjadinya fase remodeling (Bunganaen et al., 2020; Kemalasari et al., 2018). Senyawa tanin berperan sebagai astrigen dimana tanin akan menghentikan pendarahan yang terjadi pada fase hemostasis, mengurangi bengkak pada fase inflamasi, membantu menyusutkan luka dan juga bisa sebagai antibakteri (Bunganaen et al., 2020; Meliala, 2020).

Senyawa saponin berperan dalam meningkatkan kontraksi luka, meningkatkan proses epitelisasi dengan membentuk jaringan baru pada luka yang mengalami fase proliferasi dan senyawa saponin dapat meningkatkan pembentukan kolagen pada luka (Anggriawan et al., 2018; Bunganaen et al., 2020). Senyawa steroid akan berperan dalam meningkatkan proses penyembuhan luka karena memiliki aktivitas sebagai antiinflamasi dengan mengurangi bengkak pada luka yang mengalami fase inflamasi (Anggriawan et al., 20l8).

\section{Perubahan Panjang Luka}

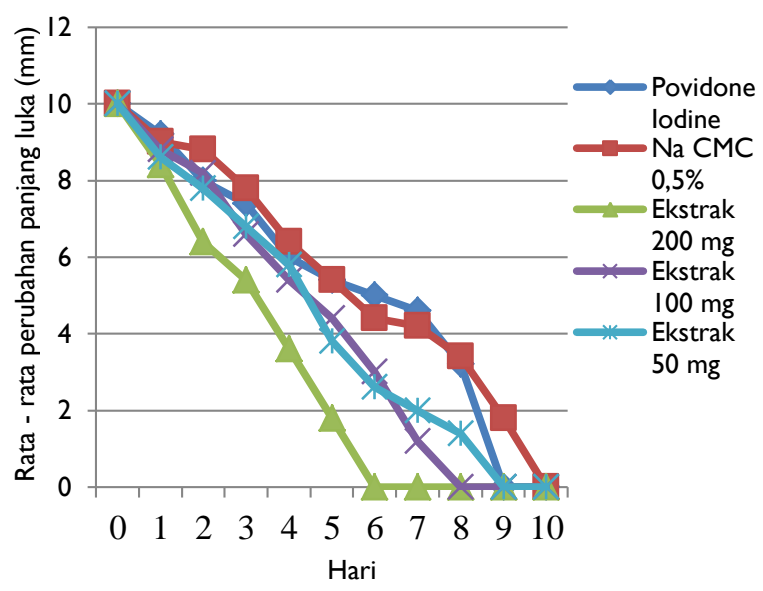

Gambar I Grafik Rata-Rata Perubahan Panjang Luka

Berdasarkan gambar I rata-rata perubahan panjang luka pada semua kelompok uji didapat dilihat bahwa kelompok ekstrak kloroform daun sangkareho (Callicarpa longifolia Lam.) dosis $200 \mathrm{mg}$ lukanya lebih cepat menutup sempurna dengan panjang $0 \mathrm{~mm}$ tanpa meninggalkan bekas luka pada hari keenam dibandingkan kelompok kontrol positif yang lukanya menutup sempurna dengan panjang 0 mm pada hari kesembilan.

Efek penyembuhan luka sayat oleh ekstrak kloroform daun sangkareho (Callicarpa longifolia Lam.) diduga akibat kandungan senyawa metabolit sekunder berada didalam ekstrak kloroform daun sangkareho (Callicarpa longifolia Lam.) bukan karena mekanisme pertahanan tubuh dari hewan uji. Hal ini dapat dibuktikan dengan hasil data yaitu ketiga dosis ekstrak memiliki efek dalam penyembuhan luka lebih cepat dibandingkan kontrol negatif. Kontrol negatif mengalami perubahan panjang luka dengan panjang $0 \mathrm{~mm}$ dimana luka menutup sempurna pada hari kesepuluh, sedangkan kelompok yang diberikan ekstrak dosis 200 $\mathrm{mg} / 200 \mathrm{grBB}$ luka menutup sempurna dengan panjang $0 \mathrm{~mm}$ pada hari keenam, dosis 100 $\mathrm{mg} / 200 \mathrm{grBB}$ pada hari kedelapan, dosis 50 mg/200grBB pada hari kesembilan dan kontrol positif pada hari kesembilan. Kelompok kontrol negatif panjang lukanya mengecil lebih lama dibandingkan kelompok uji lainnya.

\section{Percepatan Fase Luka}

Tabel II. Hasil Percepatan Fase Luka

\begin{tabular}{ccccc}
\hline Kelompok & $\begin{array}{c}\text { Fase } \\
\text { Hemostasi } \\
\text { s }\end{array}$ & $\begin{array}{c}\text { Fase } \\
\text { Inflamasi }\end{array}$ & $\begin{array}{c}\text { Fase } \\
\text { Proliferasi }\end{array}$ & $\begin{array}{c}\text { Fase } \\
\text { Remodeling }\end{array}$ \\
\hline $\begin{array}{c}\text { Kontrol } \\
(+)\end{array}$ & Hari 0-I & Hari 0-2 & Hari 3-7 & Hari 8-10 \\
\hline $\begin{array}{c}\text { Kontrol } \\
(-)\end{array}$ & Hari 0-I & Hari 0-2 & Hari 3-9 & Hari 10 \\
\hline $\begin{array}{c}\text { Ekstrak } \\
50 \mathrm{mg}\end{array}$ & Hari 0-I & Hari 0-3 & Hari 3-7 & Hari 8-10 \\
\hline $\begin{array}{c}\text { Ekstrak } \\
\text { I00 mg }\end{array}$ & Hari 0-I & Hari 0-2 & Hari 3-6 & Hari 7-10 \\
\hline $\begin{array}{c}\text { Ekstrak } \\
200 \mathrm{mg}\end{array}$ & Hari 0-I & Hari 0-2 & Hari 2-5 & Hari 6-10 \\
\hline
\end{tabular}

Pengamatan proses penyembuhan fase luka pada kelompok uji yang diberikan ekstrak kloroform 
daun sangkareho (Callicarpa longifolia Lam.) didapatkan hasil yang paling cepat mengalami fase penyembuhan luka adalah dosis tertinggi yaitu dosis $200 \mathrm{mg} / 200 \mathrm{grBB}$. Dosis $200 \mathrm{mg} / 200 \mathrm{grBB}$ lebih cepat memasuki fase proliferasi yaitu pada hari kedua sedangkan dosis $100 \mathrm{mg} / 200 \mathrm{grBB}$ dan dosis $50 \mathrm{mg} / 200 \mathrm{grBB}$ baru memasuki fase proliferasi pada hari ketiga. Dosis 200 mg/200grBB lebih cepat memasuki fase remodeling pada hari kedua dibandingkan dua dosis lainnya. Dosis 100 $\mathrm{mg} / 200 \mathrm{grBB}$ memasuki fase remodeling pada hari ketujuh dan dosis $50 \mathrm{mg} / 200 \mathrm{grBB}$ mulai memasuki fase remodeling pada hari kedelapan.

Pengamatan terhadap ciri fase penyembuhan luka didapatkan hasil bahwa dosis 200 mg/200grBB merupakan dosis yang paling efektif diantara kelompok kontrol dan kelompok uji lainnya. Pada hari kedua kelompok yang diberikan ekstrak kloroform daun sangkareho (Callicarpa longifolia Lam.) dengan dosis $200 \mathrm{mg}$ sudah memasuki fase proliferasi dan mencapai fase remodeling pada hari keenam dibandingkan dengan kontrol positif yaitu povidone iodine 10\% yang baru memasuki fase proliferasi dihari ketiga dan masuk ke fase remodeling pada hari kedelapan. Hal ini diduga diakibatkan oleh ekstrak kloroform daun sangkareho (Callicarpa longifolia Lam.) memiliki kandungan metabolit sekunder yang memiliki peran penting dalam proses penyembuhan luka sayat.

Pengamatan fase luka pada kelompok kontrol negatif terlihat bahwa kontrol negatif baru memasuki fase proliferasi pada hari ketiga dan memasuki fase remodeling pada hari kesepuluh atau pada hari terakhir. Hasil pengujian kelompok kontrol negatif luka sayat yang dialami hewan uji lebih lama sembuh dibandingkan kelompok lain. Hal ini disebabkan karena $\mathrm{Na}$ CMC 0,5\% yang digunakan pada kelompok kontrol negatif tidak memiliki efek terhadap penyembuhan luka, sehingga luka yang dialami oleh hewan uji kelompok kontrol negatif sembuh karena mekanisme pertahanan tubuh alami dari hewan uji tersebut.

\section{Analisis Data Statistik}

Hasil analisis data statistik pada kelompok ekstrak kloroform daun sangkareho (Callicarpa longifolia Lam) antara dosis $200 \mathrm{mg}$ dan $100 \mathrm{mg}$ memiliki perbedaan signifikan $(p=0,008)$ dan antara dosis $200 \mathrm{mg}$ dan $50 \mathrm{mg}$ memiliki perbedaan yang signifikan secara statistik $(p=0,008)$. Analisis data statistik pada kelompok ekstrak kloroform daun sangkareho (Callicarpa longifolia Lam) antara dosis $200 \mathrm{mg}$ dan kontrol positif terdapat perbedaan yang signifikan secara statistik $(p=0,007)$. Tidak terdapat perbedaan yang signifikan antara dosis 100 $\mathrm{mg}$ dengan dosis $50 \mathrm{mg}$ dilihat dari $p$ value $=0,164$.

\section{KESIMPULAN}

Senyawa kimia yang terkandung di dalam ekstrak kloroform daun sangkareho (Callicarpa longifolia Lam) antara lain alkaloid, flavonoid, tanin, saponin dan steroid yang berperan dalam proses penyembuhan luka. Ekstrak kloroform daun sangkareho (Callicarpa longifolia Lam.) dosis 200 mg/200grBB mengalami penutupan luka sayat menjadi $0 \mathrm{~mm}$ pada hari keenam lebih cepat dibandingkan dengan tingkatan dosis yang lebih rendah dan kelompok kontrol positif. Ekstrak kloroform daun sangkareho (Callicarpa longifolia Lam.) dosis $200 \mathrm{mg} / 200 \mathrm{grBB}$ lebih cepat memasuki fase remodeling pada hari keenam dibandingkan dua dosis lainnya dan kontrol positif. Sehingga dapat disimpulkan bahwa dosis ekstrak kloroform daun sangkareho (Callicarpa longifolia Lam.) yang paling efektif dalam penyembuhan luka sayat adalah dosis $200 \mathrm{mg} / 200 \mathrm{grBB}$. Saran untuk peneliti selanjutnya adalah perlu dilakukan pengujian lebih lanjut terkait pengamatan secara mikroskopis seperti uji hispatologi terhadap kondisi jaringan kulit pada hewan uji setelah dilakukan perlakuan luka sayat dan dilakukan pengukuran kadar 
metabolit sekunder dari ekstrak kloroform daun sangkareho (Callicarpa longifolia Lam).

\section{UCAPAN TERIMA KASIH}

Peneliti mengucapkan terimakasih dan apresiasi sebesar-besarnya kepada semua pihak yang terkait pada penelitian ini dan kepada Universitas Sari Mulia.

\section{REFERENSI}

I. RISKESDAS. (20I8). Riset Kesehatan Dasar 2018. Kementrian Kesehatan Republik Indonesia.

2. Kurniawaty, E., Farmitalia, C. G., Rahmanisa, S., \& Andriani, S. (20/8). Perbandingan Tingkat Kesembuhan Luka Sayat Terbuka antara Pemberian Etakridin Laktat dan Pemberian Propolis Secara Topikal Pada Tikus Putih (Rattus novergicus). Seminar Nasional Pakar Ke I, I, 339345.

3. Handi, P., Sriwidodo, \& Ratnawulan, S. (2017). Review Sistematik: Proses Penyembuhan dan Perawatan Luka. Farmaka Journal, I5(2), 25 I-256.

4. Sinto, L. (20/8). Scar Hipertrofik dan Keloid: Patofisiologi dan Penatalaksanaan. Cermin Dunia Kedokteran, 45(I), 29-32.

5. Ekawati, E. R., Yusmiati, S. N. H., \& Herawati, D. (20I8). Identifikasi kuman pada pus dari luka infeksi kulit. Jurnal SainHealth, 2(I), 3I-35.

6. Handayani, R., \& Natasia, G. (20/8). Uji Daya Hambat Ekstrak Etanol Daun Sangkareho (Callicarpa longifolia Lam.) Terhadap Escherichia coli. Jurnal Surya Medika Volume, 3(2), 54-6I.

7. Qamariah, N., Handayani, R., \& Khadafi, A. (20/6). Pemanfaatan Tumbuhan Sangkareho (Callicarpa longifolia Lam) Asal Kalimantan Tengah sebagai Obat Tradisional. Jurnal Surya Medika, 2(I), I4-22.

8. Susilawati, E., Aligita, W., Adnyana, I. K., Patonah, Sukmawati, I. K., Anneesha, \& Putri. (2018). Activity of karehau (Callicarpa longifolia lamk.) leaves ethanolic extract as a wound healing. Journal of Pharmaceutical Sciences and Research, I0(5), 1243-1247.

9. Supomo, Supriningrum, R., \& Junaid, R. (20/6). Karakterisasi dan Skrining Fitokimia Daun Kerehau (Callicarpa longifolia Lamk.). Jurnal Kimia Mulawarman, I3(2), 89-96.
10. Lolok, N., Awaliyah, N., \& Astuti, W. (2020). Formulasi Dan Uji Aktivitas Sediaan Sabun Cair Pembersih Kewanitaan Ekstrak Daun Waru (Hibiscus tiliaceus) Terhadap Jamur Candida albicans. Jurnal Mandala Pharmacon Indonesia, 6(0I),

59-80. https://doi.org/I0.353 I I/jmpi.v6i01.53

I I. Ikalinus, R., Widyastuti, S. K., \& Eka Setiasih, N. L. (20I5). Skrining Fitokimia Ekstrak Etanol Kulit Batang Kelor (Moringa Oleifera). Indonesia Medicus Veterinus, 4(I), 7I-79.

12. Lestiono, Kresnamurti, A., Rahmad, E., \& Riko Ansyori, M. (2020). Aktivitas Analgesik Ekstrak Etanol Bulu Babi (Echinometra Mathaei) Pada Mencit Putih Jantan. Journal of Herbal, Clinical and Pharmaceutical Science (HERCLIPS), I(2), 7-I2.

13. Sami, F. J., Soekamto, N. H., Firdaus, F., \& Latip, J. (2019). Uji Aktivitas Antioksidan Ekstrak Alga Coklat Sargassum polycystum Dan Turbinaria deccurens Asal Pulau Dutungan Sulawesi Selatan Terhadap Radikal DPPH. Jurnal Kimia Riset, 4(I), I-6.

14. Bunganaen, M. C. W., Sasputra, I. N., \& Artawan, I. M. (2020). Studi Komparatif Efektivitas Pemberian Ekstrak Daun Lamtoro(Leucaena Leucocephala) Dan Salep Gentamisinterhadap Penyembuhan Luka Sayat Kulit Mencit (Mus Musculus). Cendana Medical Journal (CMJ), 8(I), 5I2-520.

http://ejurnal.undana.ac.id/CMJ/article/view/2660

I5. Kemalasari, N., Sumardi, \& Febriani, Y. (20I8). Uji Efektivitas Flavonoid Total Ekstrak Etanol Kulit Batang Nangka (Artocarpus heterophyllus Lam) Terhadap Penyembuhan Luka Sayat Pada Ayam Broiler (Gallus domesticus). Journal of Pharmaceutical and Sciences (JPS), I(I), I-6.

16. Meliala, L. (2020). Uji Efektvitas Salep Ekstrak Etanol Rimpang Jeringau (Acorus calamus L.) Terhadap Penyembuhan Luka Sayat. Jurnal Penelitian Farmasi \& Herbal, 3(1), 13-18.

17. Anggriawan, M., Yuliet, \& Khaerati, K. (2018). Pengaruh Pemberian Topikal Ekstrak Etanol Daun Pecut Kuda ( Stachytarpheta jamaicensis ( L .) Vahl ) Terhadap Penyembuhan Luka Bakar Derajat II Pada Punggung Kelinci. Biocelebes, 12(2), 47-48.

18. Julianto, T. S. (2019). Fitokimia Tinjauan Metabolit Sekunder dan Skrining Fitokimia (Cetakan I). Universitas Islam Indonesia. 